\title{
Assessment of Diabetic Patients in a Tertiary Hospital on Knowledge, Practice of and Attitude to Lifestyle Modifications
}

\author{
Stella Folajole Usifoh ${ }^{1, *}$, Bose Ademola ${ }^{2}$ \\ ${ }^{1}$ Department of Clinical and Pharmacy Practice, Faculty of Pharmacy, University of Benin, Benin City, Nigeria. \\ 2Pharmacy Department, University College Hospital, Ibadan, Oyo State, Nigeria
}

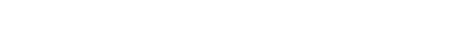

Authors' Contributions

1 Conception, Study Design, Data Analysis, and Critical Review

2 Conception, Data Collection, Data Analysis, and first Draft.
\end{abstract}

\section{Article info.}

Received: March 03, 2020

Accepted: July 07, 2020

Funding Source: Nil

Conflict of Interest: Nil

Cite this article: Usifoh SF, Ademola B.

Assessment of Diabetic Patients in a Tertiary Hospital on Knowledge, Practice of and

Attitude to Lifestyle Modifications. RADS J

Pharm Pharm Sci. 2020; 8(1):7-13.

*Address of Correspondence Author: sfusifoh@uniben.edu

\section{A B S TRACT}

Objective: To assessed the types 2 diabetic patient's knowledge, the practice of, and attitude to lifestyle modification at University College Hospital (UCH), Ibadan.

Methods: A cross-sectional descriptive study of types- 2 diabetic patients at the Medical outpatient clinic in $\mathrm{UCH}$ was done with a validated structured 48 item self-administered questionnaire that measured the socio-demographics, knowledge, practice of and attitude to lifestyle modifications. A purposive sampling of 99 consenting patients out of 103 determined with Yaro Tamane formulae was done. Data were entered into SPSS v. 21 for descriptive and inferential analysis.

Results: About $59.6 \%$ of respondents were within $\geq 60$ years age range, and $68.7 \%$ of them were females. Many (51.5\%) of them had tertiary education qualifications. On knowledge of symptoms, the majority $78(78.8 \%)$ had good knowledge and $21(21.2 \%)$ had poor knowledge of diabetes mellitus. While 64 (64.6\%) respondents had a good attitude and 35(35.4\%) had a poor attitude towards lifestyle modification. Besides, a vast majority (94.9\%) reported that lifestyle modification helps attain normal blood glucose levels, preserves life, assuage symptoms, and avert extended complications. The respondents tend to strongly agree to have a good practice of lifestyle modification with a weighted mean of 3.76 to 4.69 on a 5 point scale.

Conclusion: The majority of the respondents had good knowledge, the practice of and attitude to lifestyle modification which can help patients in altering long-term habits, eating or physical activity, and maintaining these practices as part of the management of the disorder.

Keywords: knowledge, the practice of, attitude to, lifestyle modification, type 2 diabetic patients.

\section{INTRODUCTION}

Diabetes mellitus presents as metabolic syndrome that is characterized by chronic hyperglycaemia, due to absolute or relative lack or reduced effectiveness of circulating insulin and it remains a crippling global health issue today [1]. This disorder presents with different degrees of insulin defiance and diminished insulin secretion as well as elevated production of glucose [2].

About $5-10 \%$ of all diabetes presents with Type 1 DM while type 2 the commonest form makes up for 90 - 
$95 \%$ of all conditions. The high risk is older age, the family account of diabetes, obesity, and lack of physical exercise; as the origin is multifactorial, likely genetically based with behavioral components [3]. In Africa, the prevalence of type 2 diabetes mellitus patients was about 20 million in 2013 which is projected to multiply by $2035[4,5]$.

In the sub-Saharan region, diabetes as a disease has great significance and Nigeria is most affected. This condition reduces life expectancy and quality of life of patients with more burden on them and their families are affected because most of the patients are incapable to access quality health care [6].

The management of diabetics essentially involves self-management education with lifestyle modification as well as setting goals for the glucose level. A study in Kenya done in 1982, found few (28\%) patients with good attitudes about lifestyle modification; poor dietary practice $(75 \%)$; and lack of regular exercise was $72 \%$ by respondents [7]. Thus, there had been an inadequate knowledge, attitude, and practice towards healthy lifestyles by many patients [8]. Currently, the major element in diabetic management is dietary modification, moderate physical exercises like brisk walking, and good adherence to medication which will enhance glycaemic control [9]. Therefore, the study aimed at the assessment of diabetic patients on knowledge, the practice of, and attitude to lifestyle modifications in $\mathrm{UCH}$, Ibadan.

\section{METHODS}

The study was carried out in University College Hospital $(\mathrm{UCH})$, Ibadan, one of the premier tertiary health institutions in Nigeria with over 56 service and clinical departments. A 48 item self-structured questionnaire was designed to collect data and was divided into four sections. Section A was on sociodemographic characteristics, Section $B$ was on knowledge of lifestyle modification among type 2 diabetic patients, Section $C$ was used to assess the attitude of lifestyle modification, and Section D was used to investigate the practice of lifestyle modification among type 2 diabetic patients.

The questionnaire critically scrutinized and validated by the researchers were pretested on 10 types 2 diabetic patients, necessary corrections were made and effected, for face and content validity. The reliability of the questionnaire was determined and a
Cronbach alpha coefficient of 0.78 was obtained. The pretested data was not added to the final result.

Sample size: The sample size was determined with Yaro Tamane formulae, with the estimated population of 138 types 2 diabetic patients that were receiving treatment in the medical out-patient clinic in $\mathrm{UCH}$, Ibadan, and 5\% margin of error. The calculated sample size was 103, however, only 99 respondents participated. Purposive sampling of all type 2 diabetic patients who gave their consent was done.

Ethical approval: The study was approved by the $\mathrm{UI} / \mathrm{UCH}$ Institutional Review Committee with the number, UI/UCH IRC UI/EC/18/0443. Patient informed consent was obtained and confidentiality was assured.

Inclusion Criteria: Type 2 diabetic patients who gave their consent to participate and were currently receiving treatments in $\mathrm{UCH}$, Ibadan, when this study was conducted.

Exclusion criteria: Type 2 diabetic patients who refused to participate and sign an informed consent, and those who were not currently receiving treatment in $\mathrm{UCH}$, Ibadan, when this study was conducted.

Data analysis: The self - administered validated questionnaire took about 12-15 minutes to fill, the respondent that were not literate were assisted by trained research assistants. Data were sorted and inputted into the statistical package for the social sciences (SPSS) version 20 for descriptive and inferential statistics. Also, the Likert scale was assigned numeric values of 5 to 1 . Strongly agreed $=5$, Agree $=4$, undecided $=3$, Disagree $=2$, and strongly disagree $=1$ to report a single average response for each variable.

\section{RESULTS}

The respondents' age ranged from 30 to above 60 years, and the majority (59.6\%) were above 60 years, $31(31.3 \%)$ of the respondents were males, while $68(68.7 \%)$ were females. The majority $(77.8 \%)$ of them were married, on educational qualifications, half $(51.5 \%)$ had tertiary education as their highest educational qualifications as seen in Table 1.

In Table 2, about 91(91.9\%) of the respondents reported diabetes mellitus as non-communicable disease, while $94(94.9 \%)$ of the respondents reported that diabetes mellitus is an abnormal increase in the 
blood sugar level. For knowledge score, those with $50 \%$ and above were scored as good knowledge, while those with lesser scores had poor knowledge as seen in Figure 1. Thus, the majority $78(78.8 \%)$ had good knowledge and 21(21.2\%) had poor knowledge of diabetes mellitus. Also, $98.0 \%$ reported that change in their way of life is important in the control of their condition.

Table 1. Socio-demographic Characteristics ( $\mathbf{N}=99)$.

\begin{tabular}{|c|c|c|c|}
\hline Variables & & Frequency & Percentage \\
\hline \multirow[t]{4}{*}{ Age group (years) } & 30 to 39 & 6 & 6.1 \\
\hline & 40 to 49 & 7 & 7.1 \\
\hline & 50 to 59 & 27 & 27.3 \\
\hline & $\geq 60$ & 59 & 59.6 \\
\hline \multirow[t]{2}{*}{ Sex } & Male & 31 & 31.3 \\
\hline & Female & 68 & 68.7 \\
\hline \multirow[t]{3}{*}{ Marital Status } & Single & 2 & 2.0 \\
\hline & Married & 77 & 77.8 \\
\hline & Widowed & 20 & 20.2 \\
\hline \multirow[t]{4}{*}{ Ethnicity } & Yoruba & 91 & 91.9 \\
\hline & Igbo & 5 & 5.1 \\
\hline & Hausa & 1 & 1.0 \\
\hline & Others & 2 & 2.0 \\
\hline \multirow[t]{2}{*}{ Religion } & Christianity & 56 & 56.6 \\
\hline & Islam & 43 & 43.4 \\
\hline \multirow[t]{6}{*}{ Educational qualification } & No formal education & 13 & 13.1 \\
\hline & Quranic & 4 & 4.0 \\
\hline & Primary & 15 & 15.2 \\
\hline & Secondary & 15 & 15.2 \\
\hline & Tertiary & 51 & 51.5 \\
\hline & Others & 1 & 1.0 \\
\hline \multirow[t]{8}{*}{ Occupation } & Unemployed & 4 & 4.0 \\
\hline & Farmer & 2 & 2.0 \\
\hline & Trading/business & 37 & 37.4 \\
\hline & Artisan & 4 & 4.0 \\
\hline & Civil servant & 16 & 16.2 \\
\hline & Student & 1 & 1.0 \\
\hline & Self-employed & 12 & 12.1 \\
\hline & Others & 23 & 23.2 \\
\hline \multirow[t]{7}{*}{ Monthly income in naira (A) } & $<\mathrm{A} 20,000$ & 24 & 24.2 \\
\hline & $\mathrm{A} 20,000$ to 39,000 & 27 & 27.3 \\
\hline & N 40,000 to 59,999 & 12 & 12.1 \\
\hline & 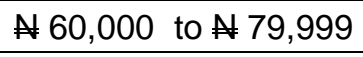 & 7 & 7.1 \\
\hline & $\mathrm{N} 80,000$ to 99,999 & 2 & 2.0 \\
\hline & $\geq \mathrm{N} 100,000$ & 17 & 17.2 \\
\hline & No response & 10 & 10.1 \\
\hline
\end{tabular}


Table 2. Respondents' knowledge.

\begin{tabular}{|l|c|c|}
\hline Respondents' Knowledge (n=99) & Yes (\%) & No (\%) \\
\hline Is diabetes mellitus a non-communicable disease? & $91(91.9)$ & $8(8.1)$ \\
\hline Is diabetes mellitus is an unusual elevation of the blood sugar level? & $94(94.9)$ & $5(5.1)$ \\
\hline $\begin{array}{l}\text { Diabetes mellitus demands special self-management behaviors throughout } \\
\text { a lifetime. }\end{array}$ & $96(97.0)$ & $3(3.0)$ \\
\hline Change in my way of life is important in the management of my condition. & $97(98.0)$ & $2(2.0)$ \\
\hline Poor management of diabetes mellitus leads to rapid disease progression. & $95(96.0)$ & $4(4.0)$ \\
\hline $\begin{array}{l}\text { Lifestyle modification is a life-long remedy and treatment for people with } \\
\text { diabetes mellitus. }\end{array}$ & $91(91.9)$ & $8(8.1)$ \\
\hline $\begin{array}{l}\text { Diabetic patients can achieve good glycaemic control by informed dietary } \\
\text { modification, suitable physical exercise, stark adherence to medication, and } \\
\text { other instructions. }\end{array}$ & $97(98.0)$ & $2(2.0)$ \\
\hline $\begin{array}{l}\text { You know that diabetic patients are at risk of dying from diabetic disorder if } \\
\text { they do not properly manage the disease. }\end{array}$ & $97(98.0)$ & $2(2.0)$ \\
\hline $\begin{array}{l}\text { You know that keeping track of glucose levels in the blood helps in the care } \\
\text { of the disorder. }\end{array}$ & $95(96.0)$ & $4(4.0)$ \\
\hline $\begin{array}{l}\text { You know that diabetes mellitus can be inherited from parents to their } \\
\text { children. }\end{array}$ & $87(87.9)$ & $12(12.1)$ \\
\hline $\begin{array}{l}\text { You know that incessant tobacco smoking and alcohol consumption is part } \\
\text { of the risk factors in diabetes mellitus disorder. }\end{array}$ & $92(92.9)$ & $7(7.1)$ \\
\hline You know that advancing in age boosts the risk of having diabetes mellitus. & $74(74.7)$ & $25(25.3)$ \\
\hline $\begin{array}{l}\text { You know that patient with diabetes mellitus passes urine frequently at } \\
\text { night. }\end{array}$ & $95(96.0)$ & $4(4.0)$ \\
\hline $\begin{array}{l}\text { You know that patients with diabetes mellitus experiences thirst and } \\
\text { dehydration. }\end{array}$ & $92(92.9)$ & $7(7.1)$ \\
\hline You know that diabetes mellitus can lead to dizziness and tiredness. & $95(96.0)$ & $4(4.0)$ \\
\hline You know that diabetes mellitus disorder can be prevented. & $95(96.0)$ & $4(4.0)$ \\
\hline
\end{tabular}

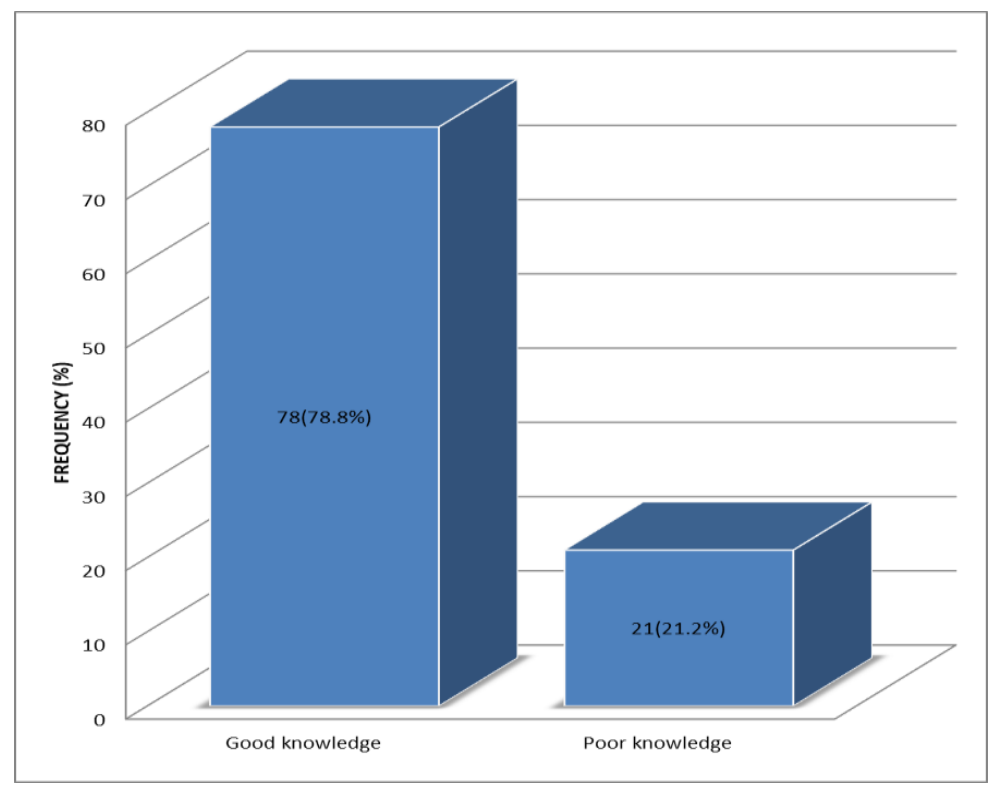

Figure 1. Summary of respondents' knowledge. 
Table 3. Respondents' attitude.

\begin{tabular}{|l|c|}
\hline Respondents' attitude (n=99) & Weighted mean \\
\hline Change in my way of life with regards to my treatment has improved my health. & 4.55 \\
\hline Patients who change their diet and eat more fiber have the chance of living longer. & 4.49 \\
\hline I am consistent in the timing of my meals and snacks. & 4.08 \\
\hline $\begin{array}{l}\text { I have achieved good glycaemic/sugar control by informed dietary modification, suitable } \\
\text { physical exercise, stark adherence to medication, and other instructions. }\end{array}$ & 4.53 \\
\hline $\begin{array}{l}\text { A healthy diet, regular exercise, keeping track of blood glucose levels, and body weight } \\
\text { are very vital in the care of diabetes mellitus. }\end{array}$ & 4.66 \\
\hline $\begin{array}{l}\text { Lifestyle modification helps to attain normal blood glucose levels, preserve life, relieve } \\
\text { symptoms, and hinder long term type 2 diabetic complications. }\end{array}$ & 4.57 \\
\hline $\begin{array}{l}\text { Lifestyle modification also involves proper bathing, drying, and lubricating the feet, } \\
\text { wearing shoes that are not too tight, and trimming toenails straight across. }\end{array}$ & 4.58 \\
\hline I do regular exercise which reduces blood glucose levels. & 4.34 \\
\hline $\begin{array}{l}\text { The dietary demands for patients with diabetes mellitus are often swayed by socio- } \\
\text { economic level, religious and cultural convictions. }\end{array}$ & 4.14 \\
\hline $\begin{array}{l}\text { Controlling blood glucose with suitable medications such as insulin has the prospect of } \\
\text { being the most effective blood-glucose-lowering remedy. }\end{array}$ & 4.39 \\
\hline Diabetes mellitus can be prevented. & 4.14 \\
\hline
\end{tabular}

Strongly Disagree=5, Agree=4, Undecided=3, Disagree $=2$ and Strongly disagree $=1$

Table 4. Respondents' practice.

\begin{tabular}{|l|c|}
\hline Respondents' practice (n=99) & Weighted mean \\
\hline $\begin{array}{l}\text { I do check my blood glucose level regularly to determine when and where changes are } \\
\text { needed. }\end{array}$ & 4.64 \\
\hline I have been coming to the clinic for medical check-ups. & 4.69 \\
\hline I do simple and physical dynamic exercises like brisk walking for 30-50 minutes daily. & 4.27 \\
\hline $\begin{array}{l}\text { I follow a controlled plan diet (I have a meal plan which is suitable for my lifestyle } \\
\text { modification). }\end{array}$ & 4.37 \\
\hline I eat at least 3 times daily with needed snacks. & 3.76 \\
\hline I do monitor my body weight regularly. & 4.23 \\
\hline I do control my blood glucose by eating a good diet. & 4.41 \\
\hline $\begin{array}{l}\text { I do proper bathing, drying, and lubricating my feet, wearing shoes that are not too tight, } \\
\text { and trimming my toenails regularly. }\end{array}$ & 4.56 \\
\hline $\begin{array}{l}\text { Daily, I carefully inspect my feet for redness, blisters, fissures, calluses, ulcerations, } \\
\text { and changes in skin temperature. }\end{array}$ & 4.15 \\
\hline $\begin{array}{l}\text { My regular keeping with hospital appointments has helped me in my blood glucose } \\
\text { level control. }\end{array}$ & 4.63 \\
\hline
\end{tabular}

Strongly Disagree=5, Agree=4, Undecided=3, Disagree $=2$ and Strongly disagree $=1$

Also, in Table 3 almost all the respondents strongly agree that diabetes mellitus requires special selfmanagement behaviours for a lifetime. About 97(98.0\%) respondents were aware that they were being treated for diabetes, while $70(70.7 \%)$ of the respondents have a comorbidity, out of these majority
(80.0\%) have hypertension, and $10.0 \%$ have high cholesterol.

For the attitude score, respondents with $50 \%$ and above were categorized as a good attitude, while those with lesser scores as poor attitude. Therefore, 
many $64(64.6 \%)$ respondents had a good attitude to lifestyle modification, and $35(35.4 \%)$ had a poor attitude towards lifestyle modification. Generally, respondent attitude towards lifestyle modification and self-care management tended to strongly agree to most of the questions asked on the change in the way of life to treatment to improve their health, eating a healthy diet, foot management, doing regular exercise and strict adherence to medication; this gave a weighted mean of 4.08 to 4.58 on a 5 -point scale that assessed their attitude as seen table 3 .

On the practice of lifestyle modification, the vast majority $(91.9 \%)$ of the respondents reported that they do check their blood glucose level consistently, $96 \%$ of them visit the clinic for medical check-ups while $83.8 \%$ do simple and suitable physical exercises such as brisk walking for thirty to 50 minutes daily. The respondents tend to strongly agree to have a good practice of lifestyle modification with a weighted mean of 3.76 to 4.69 on a 5 point scale as seen in Table 4.

\section{DISCUSSION}

The study unveiled that the great number of respondents reported that diabetes mellitus is an abnormal increase of the blood sugar level, and this agrees with the findings of Fauci et al (2012), who observed that type $2 \mathrm{DM}$ is characterized by variable degrees of insulin resistance, diminished insulin secretion, and increased glucose production [2].

The majority of diabetes mellitus patients reported frequent urination at night and is inconsonant with studies that diabetes mellitus clinical diagnosis is indicated by the presence of symptoms such as polyuria, polydipsia, and unexplained weight loss $[2,10]$.

Also, respondents had a good attitude and practice of lifestyle modification that is similar to the study where a high percentage $(98 \%)$ of patients had an average score on attitude and lifestyle modification practices [3]. The bulk of respondents opined that lifestyle modification helps to attain normal blood glucose level, preserve life, alleviate symptoms and prevent long term type 2 diabetic complications which agrees that therapeutic goal for diabetes management is to achieve normal blood glucose level, preserve life, assuage symptoms and avert extended complications [11].
Also, many respondents reported achieving good glycaemic control by strict adherence to medication and informed dietary modification this supports the findings that dietary control is a key foundation in the achievement of good glycaemic regulation in Diabetic Mellitus [12].

It was also reported eating at least 3 times daily with needed snacks and a good diet which helps regulation of the respondent's blood glucose. This agrees with ADA (2011) that to control blood glucose levels, a diabetic patient should eat meals and snacks at regular intervals daily, try not to do without or delay meals, and with regular blood glucose level measurement to ascertain the required modification [13].

Moreover, the vast majority said that lifestyle modification helps them to achieve normal blood glucose levels, thus a lifetime of special selfmanagement behaviors is essential because poor management of diabetes mellitus leads to rapid disease progression. In this study, the majority had good knowledge of diabetes mellitus, which is in contrast to the study in India where $83.3 \%$ had poor knowledge [14].

\section{CONCLUSION}

The study found the majority of diabetic patients at $\mathrm{UCH}$, had good knowledge, attitude and practice towards their lifestyle modification helps patients in altering long-term habits, eating or physical activity, and maintaining these practices as part of the management of the disorder. Therefore, a concerted effort by all healthcare practitioners in ensuring optimal care for persons with type 2 diabetes mellitus is achievable in Nigeria.

\section{REFERENCES}

1. Kumar V, Tripathi MK, Chauhan PK, Singh PK. Different non-pharmacological approaches for management of type 2 diabetes. J Diabetes. 2013; 4(1):1.

2. Fauci AS, Braunwald E, Kasper DL, Hauser SL, Longo DL, Jameson JL, et al., editors. Harrison's principles of internal medicine. 18th edition. New York: McGraw Hill. 2012; 38(12) :932

3. Ambigapathy $R$, Ambigapathy $S$, Ling HM. A knowledge, attitude \& practice (KAP) study of diabetes mellitus among patients attending Klinik 
Kesihatan Seri Manjung. NCD Malaysia. 2009; 2(2):6-16.

4. Dahiru T, Aliyu AA, Shehu AU. A review of population-based studies on diabetes mellitus in Nigeria. Sub-Saharan Afr J Med. 2016; 19(3):5964. https://doi.org/10.4103/2384-5147.184351

5. World Health Assembly. Follow-up to the Political Declaration of the High-level Meeting of the General Assembly on the Prevention and Control of Non-communicable Diseases. Geneva: World Health Organization; 2013.

6. Fasanmade, O.A; Odeniyi, I.A; Ogbera, A.O Diabetic ketoacidosis: diagnosis and management. Afr J Med Med Sci. 2008; 37(2):99-105.

7. Kiberenge WM, Ndegwa ZM, Njenga EW. Knowledge, attitude \& practices related to diabetes among community members in four provinces in Kenya. A cross-sectional study. Pan Afr Med J. 2010; 7:2. https://doi.org/10.4314/pamj.v7i1.69095

8. Okonta H.I, Ikombele J.B, Ogunbanjo G.A. Knowledge, attitudes, and practices regarding lifestyle modifications among type 2 diabetic patients attending Mamelodi Hospital, Pretoria, Gauteng, South Africa. Afr J Prim Health Care Fam Med. 2014; 6(1):655. https://doi.org/10.4102/phcfm.v6i1.655

9. Eckland, K. The newest epidemic: medication nonadherence. American J Manag care. 2013; 18(3): 49-54.

10. Adem AM, Gebremariam ET, Gelaw BK, Ahmed M, Fromsaseifu M, Thirumurugan DG. Assessment of knowledge, attitude and practices regarding life style modification among type 2 diabetic mellitus patients attending Adama Hospital Medical College, Oromia Region, Ethiopia. Glob J Med Res. 2014; 14(7):37-48.

11. Franz MJ, Powers MA, Leontos C, Holzmeister LA, Kulkarni K, Monk A, Wedel N, Gradwell E. The evidence for medical nutrition therapy for type 1 and type 2 diabetes in adults. J Am Diet Assoc. 2010;110(12):1852-89.

https://doi.org/10.1016/j.jada.2010.09.014

12. American Diabetes Association. Diagnosis and classification of Diabetes Mellitus. Diabetes Care. 2010; 33(1):S62-9. https://doi.org/10.2337/dc10S062

13. Malathy R, Narmadha M, Ramesh S. Effect of a diabetes counseling programme on knowledge, attitude \& practice among diabetic patients in Erode district of South India. J Young Pharm. 2011; 3(1):65-72. https://doi.org/10.4103/09751483.76422

14. World Health Organization: Diabetes. Available at https://www.who.int/news-room/factsheets/detail/diabetes accessed 2/7/2020.

This is an Open Access article distributed under the terms of the Creative Commons Attribution License (http://creativecommons.org/licenses/by/4.0), which permits unrestricted use, distribution, and reproduction in any medium, provided the original work is properly cited. 